\title{
PV-Transformer-Less Inverter Topology for Battery Equivalent DC Supply from Leakage Current
}

\author{
Md. N. H. Khan', Md. T. Anowar ${ }^{1}$, Md. D. Hossen ${ }^{1}$, Md. M. Alam , K. J. Ahmad \\ ${ }^{1}$ Electrical and Eloctronic Engineering, Uttara University, Bangladesh \\ ${ }^{2}$ Electrical and Computer Engineering, International Islamic University Malaysia, Kuala Lumpur
}

\begin{abstract}
Article Info
Article history:

Received Mar 22, 2016

Revised Jul 20, 2016

Accepted Aug 17, 2016

Keyword:

Adder Circuit

Fly Back Converter

Leakage Current (LC)

Low Pass Filter (LPF)

Power Inverter

Rectifier

ABSTRACT

Solar panels used for electricity generation have got inverters as their core components. Such inverters are made from switching devices coupled with additional circuit component configured in a transformer-less topology in recent reported works. A transformer-less topology suffers from the drawbacks of lack of isolation leading to leakage current flow from various points of it down to ground. The leakage in inverters might be troublesome as it may lead to loss in power, and may cause malfunctioning of analog devices normally used in power inverters. In this work, we identify possible leakage currents in a given transformer-less topology using the circuit analysis principles. The conversion of so obtained leakage currents into a useful DC voltage is carried out in this work. This work focuses on converting leakage current into small DC voltage in the range of $\sim 1.1004 \mathrm{~V}$ using recently reported rectifier circuits, supplying a load of $200 \Omega$ in the $\mathrm{mW}$ range. Although small in magnitude, such voltage sources could be used for battery charging purposes or driving small loads.
\end{abstract}

Copyright (C) 2016 Institute of Advanced Engineering and Science. All rights reserved.

\section{Corresponding Author:}

Md. N. H. Khan,

Departement of Departement of Electrical and Eloctronic Engineering,

Uttara University,

House-4 \& 6, Road-15, Sector-6, Uttara Model Town, Uttara, Dhaka-1230, Bangladesh.

Email: nomanxp76@gmail.com

\section{INTRODUCTION}

Photovoltaic (PV) panel is becoming popular both in the number of installation of units and in the rate of power each unit may provide for use world over because of affordable costs as well as an effective and pollution free technique for renewable energy generation [1]-[2]. The main contributor in total cost has been unit price of an inverter, which has decreased considerably over the years leading to increased capacity of solar panels production [3]-[4]. The resulting voltage is made a good DC before it is used as battery sources for local consumption by loads and electronic boards. For transmission to far-off places, in majority of cases, it needs be converted into AC for getting it tied to AC grid using inverters. Reduced cost of inverters is sure to result into having a boom of solar panels replacing nuclear power generation associated with the risks plant of disasters recently happened in Japan [5]. Moreover, solar panels have been effective for electricity generation used in powering up of an Oxyhydrogen (HHO) generator is used in the combustion chamber of vehicles engine for boosting its fuel mixture and reducing fuel's consumption [6]. It has been under the serious focus of attention for residential housing schemes and for the industrial developments in the Indo-Pakistan-Bangladesh sub-continent suffering from shortfall of appropriate MW of electricity generation. In the PV panels are configured switches in transformer-less topologies saving the use of transformer such as in Z-source inverter (ZSI), and the switched boost inverter (SBI) inverters [7]-[8]. Though having reduced the overall cost and size, such transformer-less configurations suffer from the inherit issues of leakage current. The reduction of leakage current has been addressed for human safety and power-loss reason in 
contemporary literature work including the use of PWM with zero voltage switches (ZVS) [9]-[11]. Leakage current minimization is also a point being addressed in the IC designs and some of the proposed techniques are those suggesting power gating technique, CMOS design technique, RBB technique, Dual-Vt and DualTox, bit line leakage current compensation technique [10]-[12]. In order to use photovoltaic panel for charging small to big electronic devices such as laptop, mobile phone charger for a longer battery lifetime, however the leakage current is the main issue of concern [13]. Recently reported is very useful work on minimizing the power losses and cost of grid-tied solar system [13]-[17]. Although small in magnitude, but the leakage current occurring at different points of the panels have become more (or less) the reason of reducing power efficiency [18]. Efforts to this effect are already underway, particularly, for traction application in a transformer-less rectifier configuration of a DC voltage controlled by fluctuating AC signal [19] to do the front-end rectification which is based on Pulse Width- Modulation buck rectifier. However, in [20], shows and discussed the two very important and useful rectifier circuit switch are fully cross coupled and gate cross coupled using MOSFET based switches. On the contrary in this work, attention is given on how to transform the leakage into having produced a DC equivalent output. Here it is shown how much it will be if highly fluctuating leakage currents are to be reproduced as DC volts for battery charging purposes or powering small LEDs for signalling purposes. Harvesting of such leakage currents with gate cross-coupled and fully cross-coupled configuration into a viable DC supply source is the focus of work in this paper.

\section{BLOCK DIAGRAM AND CIRCUIT DESCRIPTION DETAILS}

Transformer-less configuration is a well-known inverter topology using a net of devices for a convenient transfer of electric power onto the grid with high efficiency. In Figure 1 shows the block diagram of the overall work where the switching devices are used in full bridge condition and input is $12 \mathrm{~V}$ one solar cell and this block diagram are briefly shown in Figure 2 that actually a typical configuration of photovoltaic panel system connected to an inverter

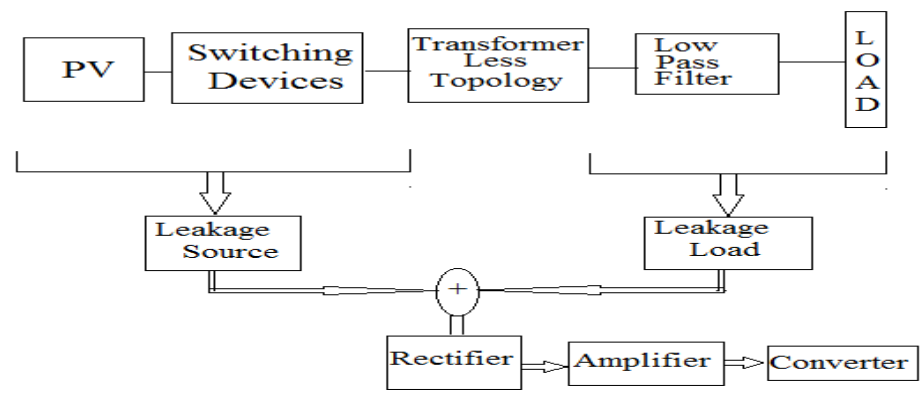

Figure 1. Block diagram of overall system

A near to DC output from the solar panel is converted into a square wave shaped output for passing it through a transformer-less topology of an inverter serving a resistive load. A higher-order low pass filter (HOLPFs) is used for making this signal transformed into an equivalent pure sine wave. It is shown that each of the blocks indicated, is shown with leakage currents passing into the ground through capacitance coupling paths. All of these leakage signals are collected into having produced an overall square-wave output using assumer circuit. The square-wave so obtained is passed through a Low-pass filter to get it in sine wave form. Subsequently, a passive rectifier circuit is used for converting it into an approximately DC output voltage that is found to be suffering from a level of fluctuations not a desirable feature for applications in some DC output supplies. A fly-back DC/DC converter is used for converting it into a purely DC output.

\section{SIMULATION TECHNIQUE OF LEAKAGE CURRENT}

In Figure 2 are shown nine paths where leakage current flow from different points into ground. In below where shows the wave shapes of different paths of leakage current. The leakage currents of an inverter side as showing and when switches are in ON condition while another path shows low on current. Meanwhile, the leakage currents of an inverter side as showing is zero current in the time of switching off time, but the Leakage current of an inverter side as showing is very amount of current in the time of switching off. The leakage issue also occurred in between PV panel sides where the current can be seen as like as the inverter. Moreover, the amount of the current is remained pico range. The leakage current between 
switches S1, S2 and S1, S4 respectively has been shown in Figure 2. These two leakage paths are the flowing leakage current only for different switches condition. Moreover, the wave shape for these two paths are shown approximately as like as fluctuated sine wave in different magnitude where the values are very small. In addition, the leakage paths are also shown in two sides of transformer less components.These two paths are actually infected by much fluctuated current where the values are in pico Ampere (pA) range.

Other two leakage issues occur correspondingly from the load to ground as shown. This current is too very much negligible where the current is flown on both sides in less than femto range on the other hand before using low pass filter the current wave shape is shown same like sine wave where it fluctuated in some portion. Furthermore, the range of flowing current is also very negligible which is occurred in between high orders LPF and ground.

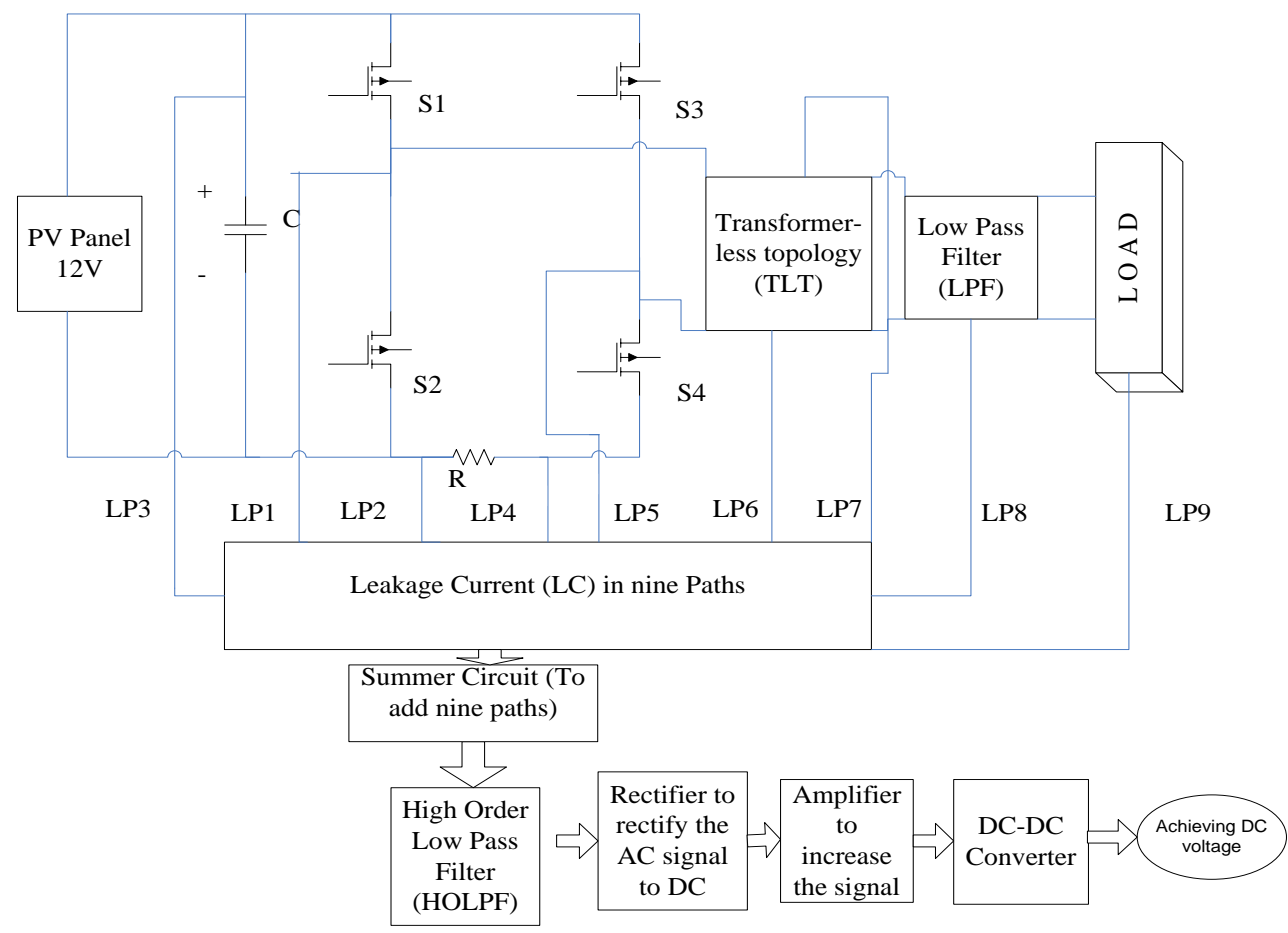

Figure 2. A circuit schematic of over all working technique

\section{COLLECTING THE LEAKAGE CURRENT FROM DIFFERENT PLACES}

The leakage currents thus collected can be used for producing a DC voltage large enough for driving small loads or charging their batteries. Assume ideal operating conditions under which capacitances, resistances and switches (MOSFET) are networked such that their parasitic effects or those due their threshold drops are ignored. The resulting leakages current if not used properly is going to drain anyway. Taking only leakage current while ignoring affects or influence by external components (such as inductors, resistors, capacitors, switches, etc.) might be having on the results, if any. Under such ideal conditions, we assumed $\mathrm{XL}=0.31416 \Omega$ and $\mathrm{X}_{\mathrm{C}}=3.1931 \Omega$ for an inductor of $1 \mathrm{mH}$ and a capacitor of $1 \mathrm{mF}$ respectively at $50 \mathrm{~Hz}$ frequency.

In the transformer-less topology there are shown five leakage current paths, while the remaining four paths include those from load or HOLPF and transformer-less technique. The cutoff frequency for HORLPF using $0.1 \mathrm{mF}$ capacitor and $10 \Omega$, the cutoff frequency point of 0.707 of the maximum (or $-3 \mathrm{~dB}$ of the pass band) is $5032.919 \mathrm{~Hz}$ for third order. The frequency components making up the sharp corners of the pulses are rounded off accordingly. Now here consider the parasitic capacitor is $1 \mathrm{nF}$ and load is $200 \Omega$. However, in Figure 2 is shown a resistance in between two side of an inverter. Here assume that resistance is $\mathrm{R}=10 \mathrm{~K} \Omega$.

\section{Inverter Side:}

The two leakage current paths from the bottom of the inverter being in $\Delta$-network fashion, is converted into an equivalent Y-network that has been shown in Figure 3a. 


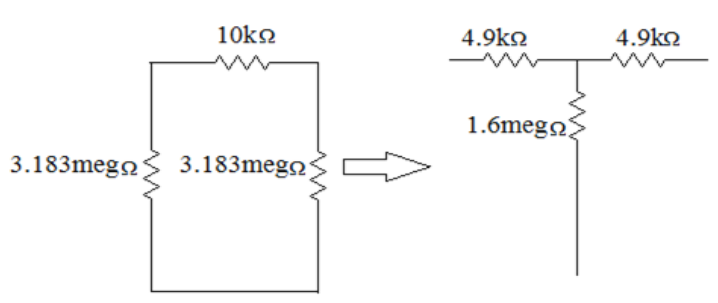

Figure 3a. Delta-to-Wye conversion for impedance calculation

The positive half-cycle conduction path (as shown in Figure 3b) through the inverter is as shown Figure 3b. In the time of positive cycle of the Inverter, switches S1 and S4 are on and getting current from different paths are as shown in Figure 3c.

$$
\mathrm{Z}_{\mathrm{EQU}(+)}=[(4900+3183091) \|(200+4900)]+1600000=1.61 \operatorname{meg} \Omega
$$

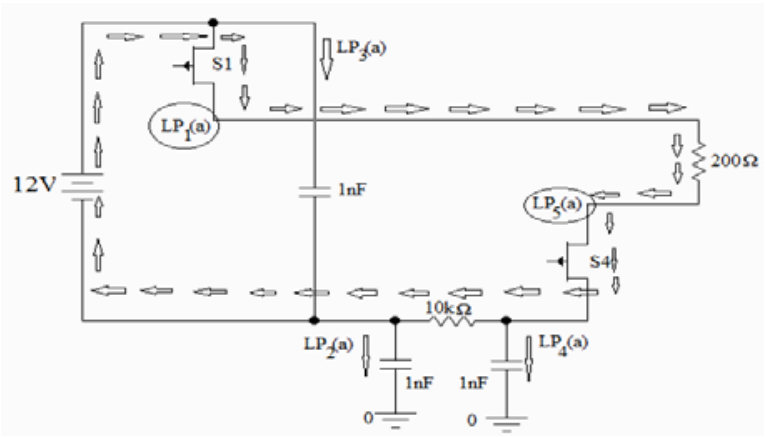

Figure 3b. Positive half-cycle path when switches S1 and S2 are closed

$$
\begin{aligned}
& \mathrm{I}=\frac{12}{1610000}=.5 \mu \\
& \mathrm{LP}_{1(\mathrm{a})}=7.49986 \mu \mathrm{A}, \mathrm{LP}_{5(\mathrm{a})}=7.49986 \mu \mathrm{A}, \\
& \mathrm{LP}_{2(\mathrm{a})}=37.4 \mathrm{pA}, \mathrm{LP}_{4(\mathrm{a})}=0.235 \mathrm{nA} \text { and } \\
& \mathrm{LP}_{3(\mathrm{a})}=0.1194 \mathrm{nA}
\end{aligned}
$$

In the time of negative cycle of the Inverter, switch S3 and S2 are on and getting current from different paths is shown below.

$$
\begin{aligned}
& \mathrm{Z}_{\mathrm{EQU}(-)}=199.98 \Omega \\
& \mathrm{LP}_{3(\mathrm{~b})}=-47.122 \mathrm{nA}, \mathrm{LP}_{1(\mathrm{~b})}=-7.49953 \mu \mathrm{A}, \mathrm{LP}_{5(\mathrm{~b})} \\
& =-7.49953 \mu \mathrm{A}
\end{aligned}
$$

Now the total currents for five paths of the inverter are in below,

$$
\mathrm{LP}_{1}=33 n \mathrm{~A}, \mathrm{LP}_{2}=37.4 \mathrm{pA}, \mathrm{LP}_{3}=-0.47 \mathrm{nA}, \mathrm{LP}_{4}=-0.235 \mathrm{nA}, \mathrm{LP}_{5}=33 \mathrm{nA} \text {. }
$$




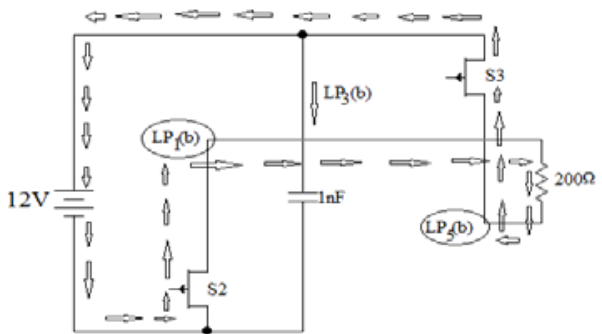

Figure 3c. Negative half-cycle path when switches S3 and S4 are closed

\section{Transformer-Less topology:}

The transformer-less technique is implemented as consisting of deriving pulses from an inverter, and applying to them to series of inductor capacitor sections sand-witched in between the output of inverter and the load. The equivalent circuit diagram is shown in Figure 3d.

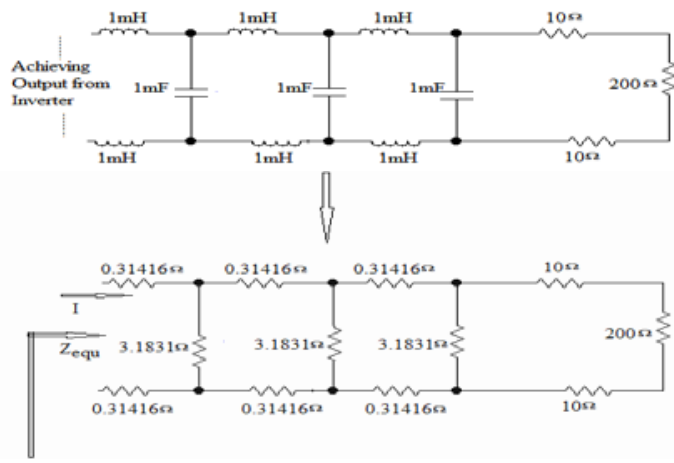

Figure 3d. Transformer-less topology used for getting equivalent impedance

$\mathrm{Z}_{\text {equ }}=1.9813 \Omega$

$I=\frac{V}{Z_{\text {equ }}}=\frac{12 * 10^{-9}}{1.9813}$

$=6.06 \mathrm{nA}$

$\mathrm{LP}_{6}=\frac{3.183 * 10^{6} * 6.06 * 10^{-9}}{3.183 * 10^{6}+3.183 * 10^{6}}=3.03 \mathrm{nA}$

$\mathrm{LP}_{6}=\mathrm{LP}_{7}=3.03 \mathrm{nA}$

The increase in input is due to the leakage being taking place through the two leakage paths.

\section{Load and Low Pass Filter (LPF) Side:}

The voltage at the output of the transformer-less section is calculated to be at 5.08nVacross an impedance of $3.1831 \mathrm{ohm}$ which forces a current of 23.01pA into a resistive load of 220ohm and the circuit of flowing current through load and HOLPF are shown in Figure 3e and 3f respectively.

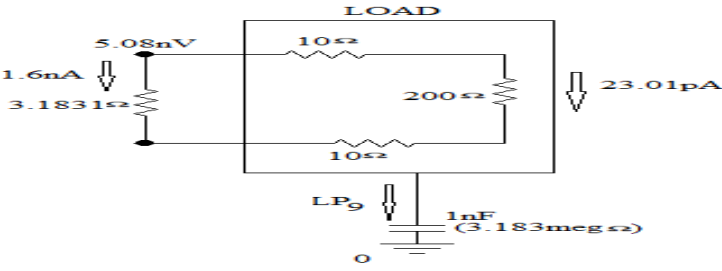

Figure 3e. Showing path of leakage current for load 


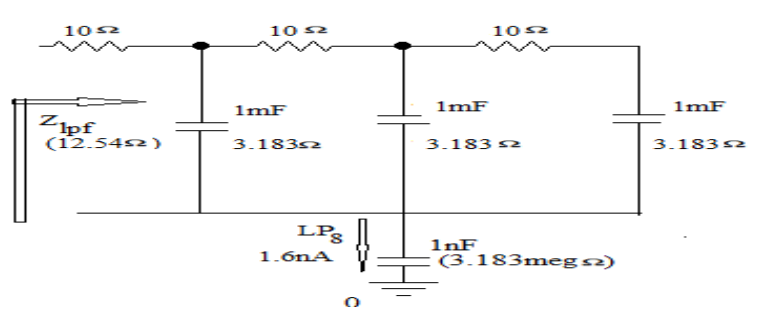

Figure 3f. Equivalent impedance for third order low pass filters

The leakage current for the filter (when get connected) can be calculated from the load leakage current using inverse-impedance proportional technique for current distribution is given asIn above, we got current of nine paths of leakage issues. Now these nine paths current have to be summed up using a summer circuit. Here used non-inverting summer circuit where the inputs are connected to resistance and achieving voltage is adding results of all nine paths. To do so, here showing the adding results of leakage issues.

\section{RESULT AND DISCUSSION}

Leakage current occurs through parasitic capacitors. This current actually has got fluctuating current that has become the reason of concern in main system. Hence, increases the lost, cost as well as decreases the power efficiency. In contrast, this fluctuated current can be used in useable form for useful purposes. In above, it is shown a system where actually around nine places occurred leakage issues. The adder circuit which is used to add these nine signals to make it one which is around more than one Volt AC signal used high orders LPFs to make it pure sine wave. Rectified used to convert this sine wave to DC signal.

$\mathrm{LI}=(\mathrm{LI}-1+\mathrm{LI}-2+\mathrm{LI}-3+\mathrm{LI}-4+\mathrm{LI}-5+\mathrm{LI}-6+\mathrm{LI}-7+\mathrm{LI}-8+\mathrm{LI}--9)$

$=\left(33 * 10^{-9}+37.4 * 10^{-12}-0.47 * 10^{-9}-0.235^{*} 10^{-9}+33^{*} 10^{-9}+3.03 * 10^{-9}+3.03 * 10^{-9}+1.6^{*} 10^{-9}+\right.$ $\left.23.01 * 10^{-12}\right)=7.302 * 10^{-8} \mathrm{~A}=0.73 \mathrm{nA}$

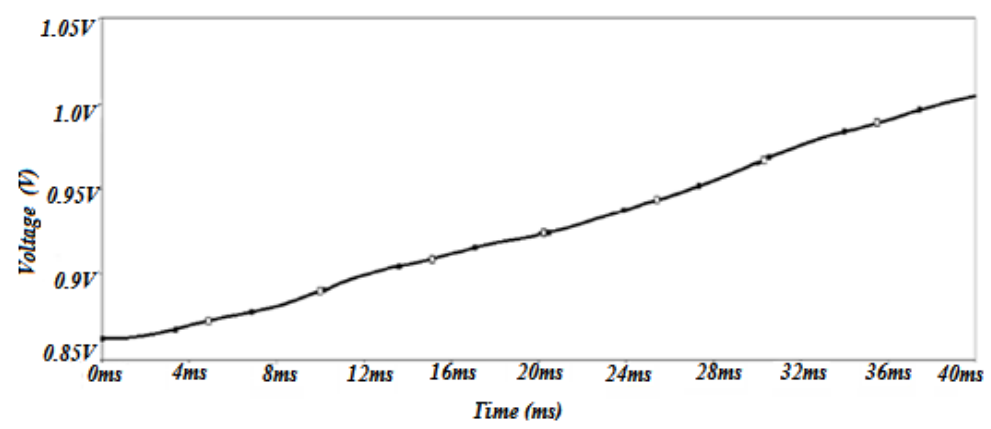

Figure 4. Figure of overall voltage for leakage paths after adding nine paths of leakage current

Now, with achieving those nine paths of leakage current and overall voltage for leakage current has been added with adder circuits and used HOLPFs to get a smooth waveform where rectifier is used to convert the achieving AC signal to DC, here is used FCC rectifier. Hence, the achieving DC voltage is as shown in Figure, but it can be smoother and clear if here use DC-DC converter for getting fluctuating less DC signal. Finally the achieving DC signals is more than $1 \mathrm{~V}$ that showing in Figure 4. However, it can be more smooth and steady through using DC-DC converter.

In above has shown the analytical equations of leakage current that occurred in nine places in a transformer-less PV panel system. After achieving these nice paths of leakage current (LC) values, here used adder to add these nice paths analytically. Now add all of those leakages current to get overall leakage current where ignoring the other external effects such as switching loss, capacitor loss, loss across load and so on.

Fully cross coupled rectifier [15] gives very good output when we applied a sine wave of amplitude $1 \mathrm{~V}$ input with achieving output around $1 \mathrm{v}$ for one cycle, however, the gate cross-coupled rectifier gives an 
around $600 \mathrm{mV}$. In the case of using FCCR, we got the high achieving values compared to use GCCR. In our case, we used the FCCR due to get highly rectification curve, which is as clear as understanding. Moreover, in the case of threshold voltage, it is possible to solve the threshold voltage drop problem by using the FCCR whereas it's impossible to use GCCR [15].

\section{CONCLUSION}

Solar panels associated with additional elements are used as renewable energy sources both in the number of unit installations and in the rated power of each unit larger than ever before. The resulting nearly DC is converted into AC for injecting solar generated power into electricity grid. The core component in such solar-to-grid connectivity is the inverter made from PWM-controlled switching devices configured in a known topology, among which transformer-less topology though has been a huge success when compared to transformer-based inverters connected to the grid. Though it is used for renewable DG generation, but it suffers from the problem of leakage current. In this work is shown how power loss to leakage currents can become a usable utility for battery charging purposes of small voltage batteries. To do so, here are shown different leakage current paths for making a DC voltage. The leakage currents from a number of such points are collected to produce a DC having a high percentage of fluctuations which are then better rectified by using a DC-DC converter. Using cross-coupled rectifier, the power transferred to a load of $100.02 \mathrm{k} \Omega$ is shown to be in the $\mathrm{mW}$ range. This amount of power is enough to be used for powering devices with small energy requirements, reducing power loss besides having electronic devices suffering from the problem of malfunction.

\section{REFERENCES}

[1] Y. Wang and J. Song, "Design of a Digital Solar Panel Automatic Tracking Controller for Photovoltaic Generation System,” Power and Energy Engineering Conference (APPEEC), Asia-Pacific, pp. 1-4, 2012.

[2] R. F. Pantelimonet, et al., "Aspects Regarding Solar Battery Charge Controllers," Advanced Topics in Electrical Engineering (ATEE) 8th International Symposium on, pp. 1-6, 2013.

[3] S. B. Kjaer, et al., "A Review of Single-Phase Grid-Connected Inverters for Photovoltaic Modules," Industry Applications, IEEE Transactions on, vol/issue: 41(5), pp. 1292-1306, 2005.

[4] P. Phonrattanasak, et al., "Optimal location and sizing of solar farm on Japan east power system using multiobjective Bees algorithm,” Energytech, IEEE, pp. 1-6, 2013.

[5] M. N. H. Khan, et al., "Leakage Current Paths in PV Transformer-Less Single-Phase Inverter Topology and Its Mitigation through PWM for Switching,” International Journal of Power Electronics and Drive Systems, vol/issue: 6(1), pp. 148-159, 2015.

[6] N. S. Jamoshidet, et al., "Solar-operated Hydrogen Assisted Combustion Using Solar PV Panel to Reduce Vehicle's Fuel Consumption," IEEE 7th International Power Engineering and Optimization Conference (PEOCO2013), Langkawi, Malaysia. 3-4 June, pp. 139-143, 2013.

[7] L. Ma, et al., "Leakage current analysis of a single-phase transformer-less PV inverter connected to the grid," Sustainable Energy Technologies, IEEE International Conference on, pp. 285-28, 2008.

[8] A. Ravindranath, et al., "Analysis and PWM Control of Switched Boost Inverter," IEEE Transactions on Inductrial Electronics, vol/issue: 60(12), pp. 5593-5602, 2013.

[9] B. R. Lin and C. C. Chien, "Analysis and implementation of a new soft switching DC/DC PWM converter," IET Power Electron, vol/issue: 6(1), pp. 202-213, 2013.

[10] M. J. Rani, S. Malarkkan, "Leakage Power Reduction in CMOS Modulo4 adder and Modulo4 Multiplier in Submicron Technology," Sustainable Energy and Intelligent Systems, International Conference on, pp. 593-597, 2011.

[11] M. N. H. Khan, et al., "Evaluation of Various Leakage Current Paths with Different Switching Conditions," in Computer and Communication Engineering, 2014 International Conference on IEEE, pp. 269-272, 2014.

[12] M. N. H. Khan, et al, "Double PWM Source Inverter Technique with Reduced Leakage Current for Application on Standalone Systems,”World Academy of Science, Engineering and Technology, vol/issue: 9(2), pp. 1602-1607, 2015

[13] A. Abdollahi, et al., "Leakage Current Reduction in CMOS VLSI Circuits by Input Vector Control," IEEE Transactions on Vert Large Scale Integration (VLSI) Systems, vol/issue: 12(2), pp. 140-154, 2004.

[14] M. N. H. Khan, et al., "Wave Shaping with Reduced Leakage Current in Transformer-less Inverter," Smart Instrumentation, Measurement and Applications (ICSIMA), IEEE International Conference on, pp. 1-5, 2013.

[15] M. N. H. Khan, et al., "DC-AC Inverter with Perspective of Common Mode and Wave-Shaping," Smart Instrumentation, Measurement and Applications (ICSIMA), IEEE International Conference on, pp. 1-5, 2013.

[16] D. O. Lopez, et al., "Eliminating ground current in a transformerless photovoltaic application," IEEE Trans. Energy Con-version, vol/issue: 25(1), pp. 140-147, 2010.

[17] H. Xiao, et al., “An optimized transformerless photovoltaic grid-connected inverter," IEEE Trans. Ind. Electron. Vol/issue: 58(5), pp. 1887-1895, 2011.

[18] M. N. H. Khan, et al., "Effect of Leakage Current in the PV Transformer-Less Inverter Topology," International Journal of Engineering Science, vol/issue: 6(4), pp. 3272-3275, 2016. 
[19] P. Chaudhary and P. Sensarma, "Front-End Buck Rectifier with Reduced Filter Size and Single-Loop Control," IEEE Transactions on Industrial Electronics, vol/issue: 60(10), pp. 4359-4368, 2013.

[20] S. S. Hashemi, et al., "A High-Efficiency Low-Voltage CMOS Rectifier for Harvesting Energy in Implantable Devices," IEEE Transactions on Biomedical Circuits and Systems, vol/issue: 6(4), pp. 326-335, 2012.

\section{BIOGRAPHIES OF AUTHORS}
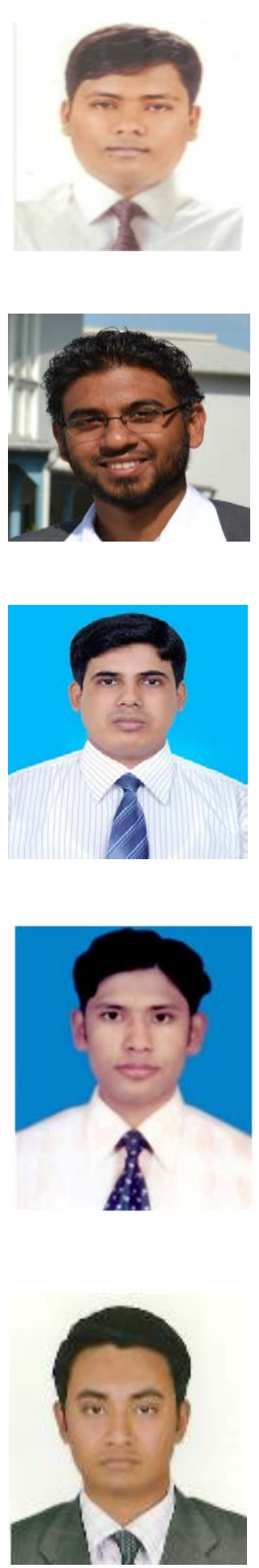

Md. Noman Habib Khan received the B.Sc degree in Electrical and Electronic Engineering (EEE) from Ahsanullah University Science and Technology (AUST), Bangladesh in 2009. However, he already finished his M.Sc degree from International Islamic University Malaysia (IIUM), Malaysia at 2014 and had been doing work as a research assistant at UMPEDAC department at University of Malaya (UM) with renewable energy especially solar, hydro, wind and hybrid for electrification issue. Now at present, he is doing work as a Lecturer in the Department of Electrical and Electronic Engineering (EEE), Uttara University (UU), Dhaka, Bangladesh.

Md. Taosif Anower received his B.Sc degree in Electrical and Electronic Engineering (EEE) from American International University-Bangladesh (AIUB), Bangladesh in 2010 and did his masters from Linkoping University, Sweden in 2013 where the major was Telecommunications. $\mathrm{He}$ is currently serving as a Lecturer in the Department of and Electronic Engineering Engineering, Uttara University (UU), Dhaka, Bangladesh.

Md. Delwar Hossen received his B.Sc degree in Electrical and Electronic Engineering (EEE) from Stamford University, Bangladesh in 2006 and M.Sc. (Continuing) in Electrical and Electronic Engineering (EEE) from Islamic University of Technology (IUT), Bangladesh. He is currently serving as Assistant Professor from Nov 2012 to present and Lecturer from Feb 2009 to Oct 2012 in the Department of and Electronic Engineering Engineering, Uttara University (UU), Dhaka, Bangladesh. Previously (Nov 2007 to Jan 2009) he was a Lecturer in the Department of Electrical and Electronic Engineering Engineering (EEE), Atish Dipankar University of Science and Technology (ADUST), Dhaka, Bangladesh.

Md. Moiful Alam earned his B.Sc. (Honors) degree in Physics from Jagannath University (JnU), Dhaka, Bangladesh in 2006 (Exam held in 2008). However, he already finished the M.Sc. (Thesis) degree in Physics from Jagannath University (JnU), Dhaka, Bangladesh in 2007 (Exam held in 2010) and had been doing research based on solar photo-voltaic system, deterioration of solar cell and SP V economics. Furthermore, he received another MS degree in Biomedical Engineering from Dhaka University (DU), Dhaka, Bangladesh in 2014 (Exam held in 2015). He enriched his experience with doing work as a teaching assistant (TA) at Physics department of Bangladesh University of Engineering \& Technology (BUET), Dhaka, Bangladesh. Now at present, he is doing work as a Lecturer in the Department of Electrical and Electronic Engineering (EEE), Uttara University (UU), Dhaka, Bangladesh.

Khandker Jamil Ahmed received the B.Sc degree in Electrical and Electronic Engineering from Ahsanullah University Science and Technology (AUST), Bangladesh in 2009 where his major was power. He had done the Higher Diploma from National Youth Training Academy, Bangladesh in 2011. In addition, he was working as an Assistant Engineer in Electro Group until december 2013. Now he is doing his M.Sc degree in Electrical and Computer Engineering (ECE) Department from International Islamic University Malaysia (IIUM), Malaysia at 2014. 